\title{
Factors influencing passengers' choice of transport mode to Warsaw Chopin Airport
}

\author{
Aleksandra GÓRECKA ${ }^{1}$ \\ 1 Warsaw University of Life Sciences - SGGW, Faculty of Economic Sciences
}

\begin{abstract}
Airport accessibility is an important factor for airport choice and therefore also for airport competition. When air passengers choose an itinerary, they reflect on the transport chain from door to door. Therefore, factors affecting the traveller's decision for a particular option go beyond the price and quality of air services from airport to airport. The decision for or against a particular air service and a particular airport is to a certain extent dependent on the accessibility of the airport.

The aim of the article is to present the preliminary research of factors which influence choice of transport mode used in order to reach Warsaw Chopin Airport (WAW). The hypothesis of the paper is that the most common transport modes to WAW is private transport. The data were collected based on survey distributed within passengers in May 2015. The results show that there is a relation between flight destination from WAW and distance from the point of origin to airport and also between kind of traveller and transport mode used by his/her. There is also the conclusion that the most common transport modes from and to the airport in Europe is used very rarely in Warsaw.
\end{abstract}

Key words- airport, accessibility, transport modes, Warsaw Chopin Airport

\section{INTRODUCTION}

Increasing number of air passengers and constant growth of importance of air transport in the world are the reasons for strong interest of this field by researchers. There are numbers of studies about airline business, starting from technical approaches (aircraft, airports, infrastructure) through aviation management problems (business, finances, accounting) ending on market trends and passengers preferences. The topic itself is very wide. Moreover, as the aviation business exist in a wider structures as economy, policies, country, region there are many interdisciplinary studies linking for example aviation business with regional development, society behaviour, or taxes.

One of the problem investigated is airport accessibility. The aim of this article is to present the preliminary research of passenger choice of transport mode used in order to reach Warsaw Chopin Airport (WAW).

WAW is the biggest airport in Poland located $8,5 \mathrm{~km}$ away from Warsaw city centre (fig.1). That makes it very unique in European scale, as most of the main airports in EU countries are situated outside the city boarders, and WAW is within the city limits.

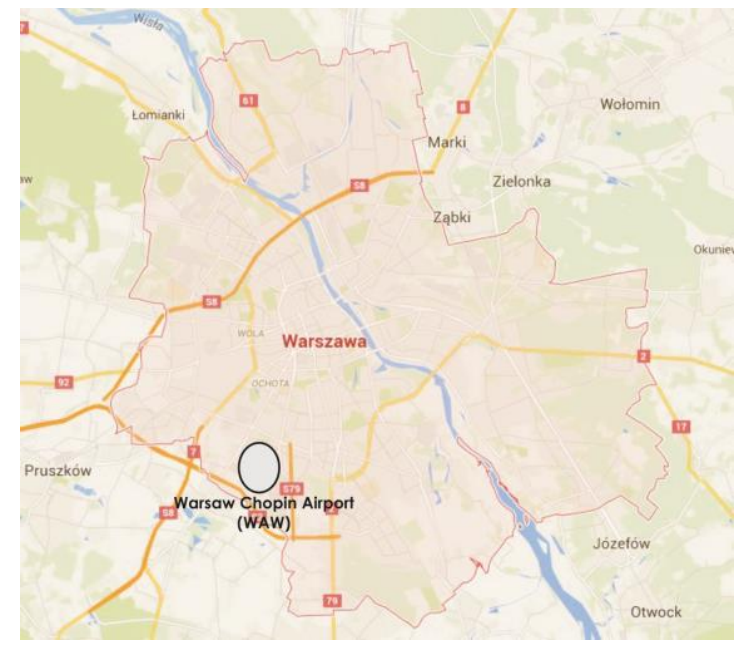

Fig.1. Location of Warsaw Chopin Airport Source: picture based on maps.google.com 
WAW handles $36,6 \%$ of the country's air passenger traffic. The total number of handled passengers has raised since 2005 to achieve the level of over $11 \mathrm{mln}$ in 2015 (fig.2). Approximately 300 scheduled flights daily are handled and an ever rising number of charters.

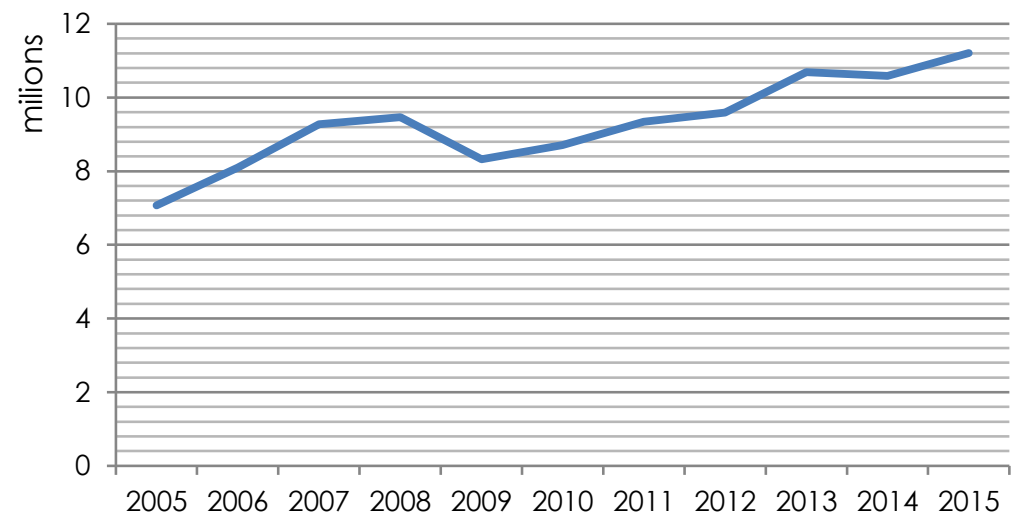

Fig.2. Number of passengers handled in Warsaw Chopin Airport in 2005-2015 Source: own research based on data from Central Statistical Office of Poland

Public and private transport modes are possible to access 2 WAW terminal buildings. First group consists of private cars and taxis. There is a special line for taxis for leaving and picking up passengers. Besides, there are also "kiss\&ride" zone and short and long-term parking lots. Public transport is represented by:

- city transport modes: 3 city bus lines $(148,188,175)$,

- agglomeration rail connections offered by SKM

- Mazovian regional rails by KM,

- numerous long-distance bus connections.

The underground railway station connected to Warsaw's suburban rail system and new bus station were opened in June 2012. As the airport is located in the city, there is no shuttle bus service dedicated for WAW passengers only, however there is a shuttle bus to the second Warsaw airport - Modlin. As it might be seen, there are standard transport modes to WAW.

\section{LITERATURE REVIEW}

Previous studies have investigated the choice of transport modes to different airports in the World. Commonly, the results showed that private car is the transport mode used for majority of passengers in USA. The case of Chicago airports [1] presents that 50\%-57\% of Chicago flight passengers use cars to arrive terminal buildings. Studies from San Francisco, San Jose and Oakland summered by Tam et al. [2] proofed US passengers preferences. Cars had the largest market share (47\%) there. Very low market share of public transport in US (10-15\%) was also pointed out by Mandle at al. [3]. On the contrary, in Asia the results were quite different as public transport accounts for over $60 \%$ of airport ground access market [3].

Apart from the transport modes market share results, researchers developed statistical models in order to determine significant factors affecting the airport ground access mode choice. Different parameters were taken under consideration as: travel costs, time, socio-demographic indicators etc. Foote et al. [4] investigated factors affected usage of rail transit and concluded that costs, time and being close by are the most important factors for air passengers. The results of Caves et al. [5] and Psaraki and Abacourucmin [6] underlined the importance of time and travel costs too. Jou et al. [7] presented the possibility of using MRT system (light rapid rail transit) in Northen Thailand, as an contraire to classic transport access mode. The results showed new parameters statistically significant for passengers while choosing the transport modes like: in-vehicle and out-of-vehicle time.

Tam et al. [8] found that the travel time reliability is a positive parameter which indicates that the satisfaction with a certain mode increases. Nevertheless, there are studies which show that there is a low willingness of paying more to save the travel time to the airport [9]. Akar [10] presented top five factors influencing transportation other that automobile, and these were: reliability, shorter travel time to the airport, flexibility of departure time, comfort and luggage storage capacity. 


\section{RESEARCH METHODS}

For this research preliminary data was collected based on interview with passengers in May 2014. 70 passengers of WAW departure zone were interviewed within one week on: Monday 8-11 am, Wednesday 11 am-3 pm, Friday 3-8 pm and Saturday 10 am-5 pm.

The statistical analysis consisted on simple statistical methods, Spearman correlation. The main analysis is classification tree. Regression trees have a non-categorical and numerical target variable and aim to divide up the data into sub-setting rectangles that are homogeneous with respect to the response. In efforts to attain this homogeneity regression tree algorithms will decide which predictors are important and are to be split, at which value of the predictor the split should occur, how deep the tree should be (i.e. how many layers of internal nodes are needed), how complex the tree should be (i.e. how many branches are needed), and provide a prediction equation for each terminal node [11]. The flexibility of classification trees make them a very attractive analysis option, but this is not to say that their use is recommended to the exclusion of more traditional methods. Indeed, when the typically more stringent theoretical and distributional assumptions of more traditional methods are met, the traditional methods may be preferable. But as an exploratory technique, or as a technique of last resort when traditional methods fail, classification trees are, in the opinion of many researchers, unsurpassed [12].

The tree is a graphic model resulting from the division of the set recursive $A$ follow-on $n$ disjoint subsets $A_{1}, A_{2}, A_{3}, \ldots, A_{n}$. The construction of the model is obtaining a maximum homogeneous subsets from the variable point of view. This is a multi-step process. On each stage it is analyzed for all predictors and selects the one that provides the best node division $[13,14]$.

To create regression tree model there were the following assumption. Transport mode to the airport was dependent $(y)$, and there were 8 independent variables including into the model:

$\mathrm{x}_{1}$ - travel time to WAW (1 - <10 min; 2 - 11-30 min; 3 - 31-59 min; 4 - 1-1,5h; 5 - 1,5-3h; 6 - >3h)

$x_{2}$ - distance from the beginning of the trip to WAW (in kilometres),

$x_{3}$ - travel costs (in EUR),

$\mathrm{X}_{4}$ - travel satisfaction (Likert scale - from 1 as very unsatisfied to 5 - very satisfied),

$x_{5}$ - flight destination (1 - short-haul flight, 2 - medium-haul flight, 3 - long-haul flight' ${ }^{1}$ )

$x_{6}$ - purpose of air travel (1 - private; 2 - business),

$x_{7}$ - length of staying in destination (days),

$x_{8}$ - travel class ( 1 - economy; 2 - business, 3 - first).

\section{RESULTS}

There were 29 places of origins of passengers interviewed. $20 \%$ of them travelled to WAW from several Warsaw districts. For $80 \%$ of them the place where they had started the journey was away from Warsaw (fig.3).

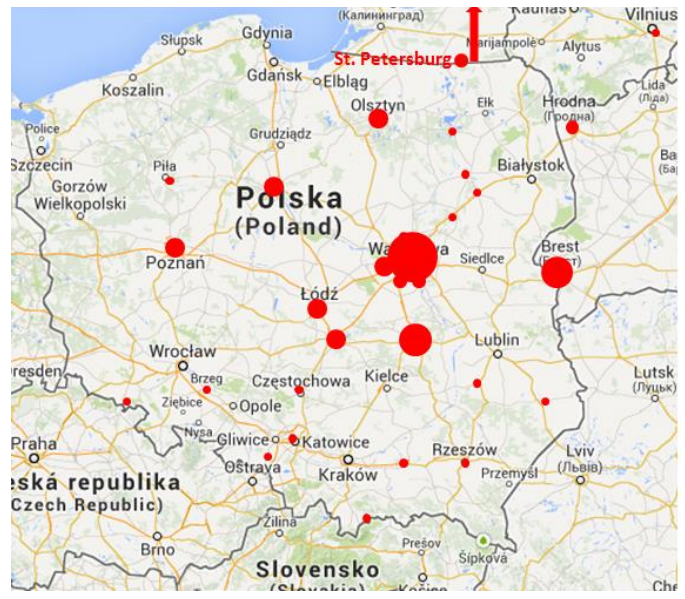

\footnotetext{
${ }^{1}$ According to Munich Airport reports: short-haul flight - up to $3500 \mathrm{~km}$, medium-haul flight - 3500-6000 km, long-haul flight - over $6000 \mathrm{~km}$.
} 
Fig.3. Started points of air passengers travel to WAW

Source: own elaboration based on data from questionnaire

Within 6 possible transport modes for WAW departure passengers $43,02 \%$ used private cars to get to their departure terminal building. None of these passengers could have estimated the cost of the travel to the airport (fig.4). Apart from that, 21,74\% of respondents used combined transport, however the last transport mode to the terminal building was taxi (66\%).

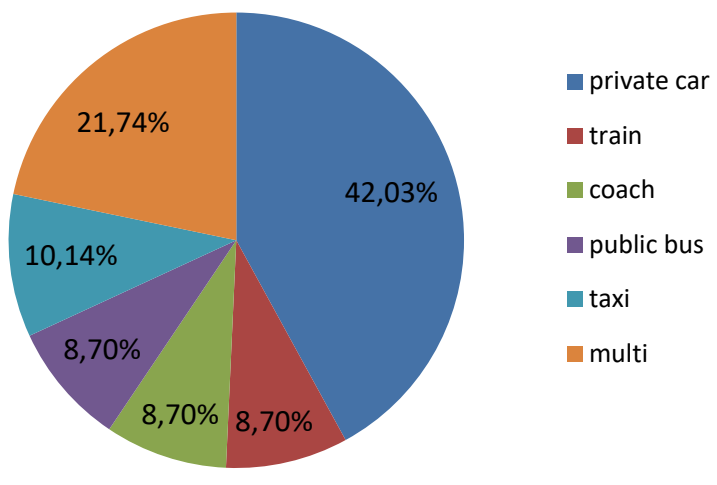

Fig.4. Transport mode used by air passengers to WAW airport Source: own elaboration based on data from questionnaire

Variable " $y$ " was qualitative date and was represented by 5 transport modes: 1 - private car, 2 - taxi, 3 - public bus, 4 - intercity bus, 5 - trains (SKM, KM).

Spearman correlation shows that only travel time to WAW correlates with chosen transport (tab.1).

Table 1. Spearmen correlation matrix for transport mode "y"

\begin{tabular}{|c|c|c|c|c|c|c|c|c|c|}
\hline \multirow[b]{2}{*}{ Variables } & \multicolumn{9}{|c|}{$\begin{array}{l}\text { Spearman correlation } \\
\text { Marked correlation coefficients are important for } p<, 05000\end{array}$} \\
\hline & $y$ & $\mathrm{x} 1$ & $x 2$ & $x 3$ & $x 4$ & $x 5$ & $x 6$ & $x 7$ & $x 8$ \\
\hline $\mathrm{y}$ & 1,000000 & $-0,141360$ & $-0,234326$ & 0,391521 & 0,156902 & 0,013399 & 0,115744 & $-0,136100$ & 0,117291 \\
\hline $\mathrm{x} 1$ & $-0,141360$ & 1,000000 & 0,855848 & 0,199691 & $-0,146806$ & $-0,153485$ & 0,276680 & 0,053244 & $-0,122200$ \\
\hline$x 2$ & $-0,234326$ & 0,855848 & 1,000000 & 0,101424 & $-0,221328$ & $-0,021856$ & 0,263262 & 0,103095 & $-0,193790$ \\
\hline$x 3$ & 0,391521 & 0,199691 & 0,101424 & 1,000000 & $-0,164025$ & 0,145694 & 0,037865 & 0,072175 & $-0,234639$ \\
\hline$x 4$ & 0,156902 & $-0,146806$ & $-0,221328$ & $-0,164025$ & 1,000000 & $-0,126844$ & $-0,241139$ & 0,122286 & 0,215406 \\
\hline$x 5$ & 0,013399 & $-0,153485$ & $-0,021856$ & 0,145694 & $-0,126844$ & 1,000000 & 0,274951 & 0,355721 & $-0,214181$ \\
\hline$x 6$ & 0,115744 & 0,276680 & 0,263262 & 0,037865 & $-0,241139$ & 0,274951 & 1,000000 & $-0,059333$ & $-0,183892$ \\
\hline$x 7$ & $-0,136100$ & 0,053244 & 0,103095 & 0,072175 & 0,122286 & 0,355721 & $-0,059333$ & 1,000000 & 0,159787 \\
\hline$x 8$ & 0,117291 & $-0,122200$ & $-0,193790$ & $-0,234639$ & 0,215406 & $-0,214181$ & $-0,183892$ & 0,159787 & 1,000000 \\
\hline
\end{tabular}

Source: own elaboration based on own research

As it was mentioned in methodology, regression tree model would investigate the homogenous groups of passengers choosing different transport mode to WAW (fig. 5) based on 8 variables. First step was to find which of the variables are statistically the most important. It occurs that distance from the beginning of the trip to WAW ( $\left.x_{2}\right)$, travel time and costs are the most important factors dividing the respondents into several groups in regression tree model (fig. 5). 
Logistics \& Sustainable Transport

Vol. 7, No. 1, October 2016, 51-57

doi: 10.1515/jlst-2016-0005

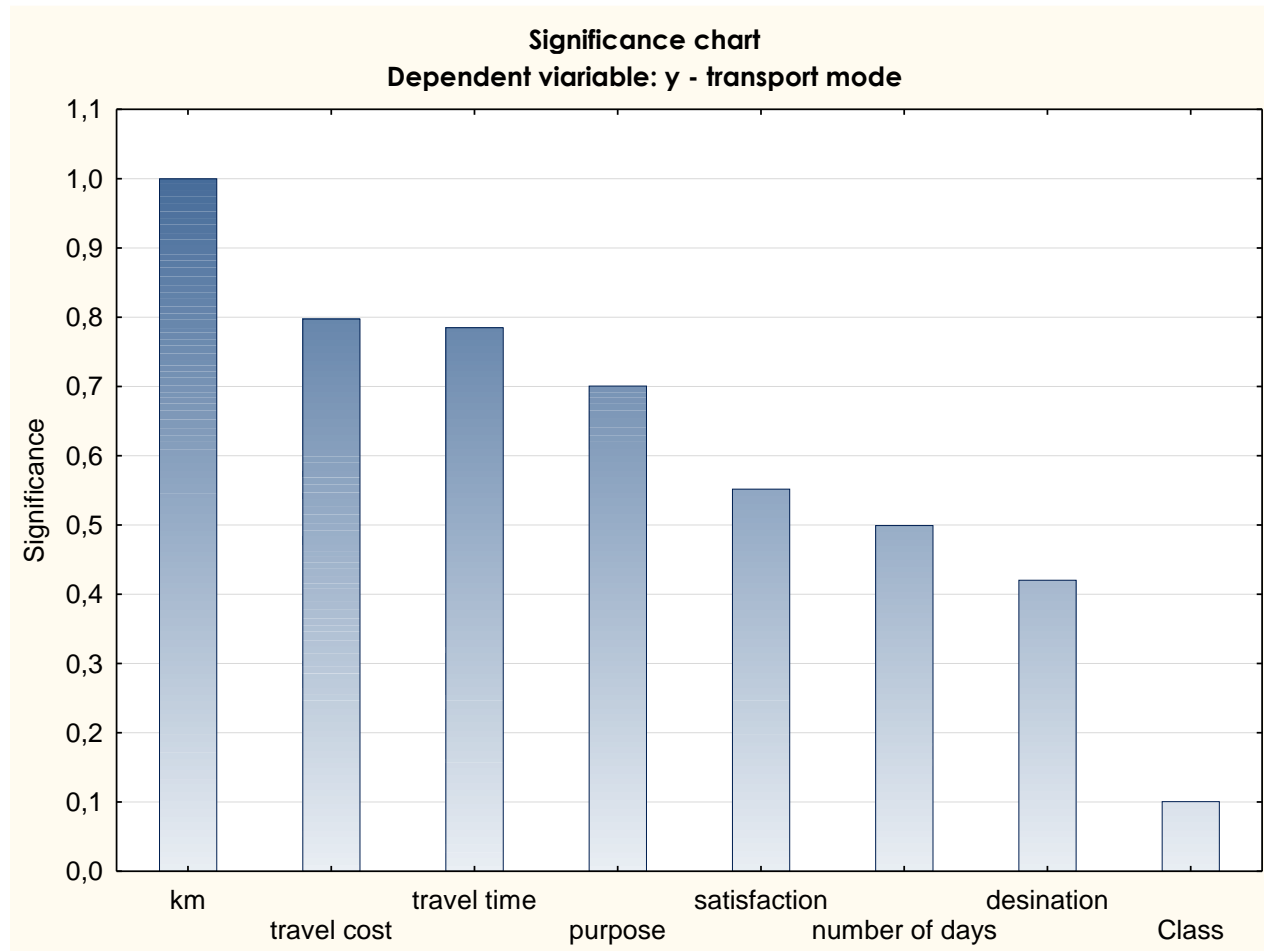

Fig. 5. Significance chart for $y$ - transport mode

Source: own elaboration based on data from questionnaire (by Statistica 12.5 software)

Regressopn tree model No 1 for: $y$ - transport mode

Number of nodes split $=4$; Number of terminal nodes $=5$

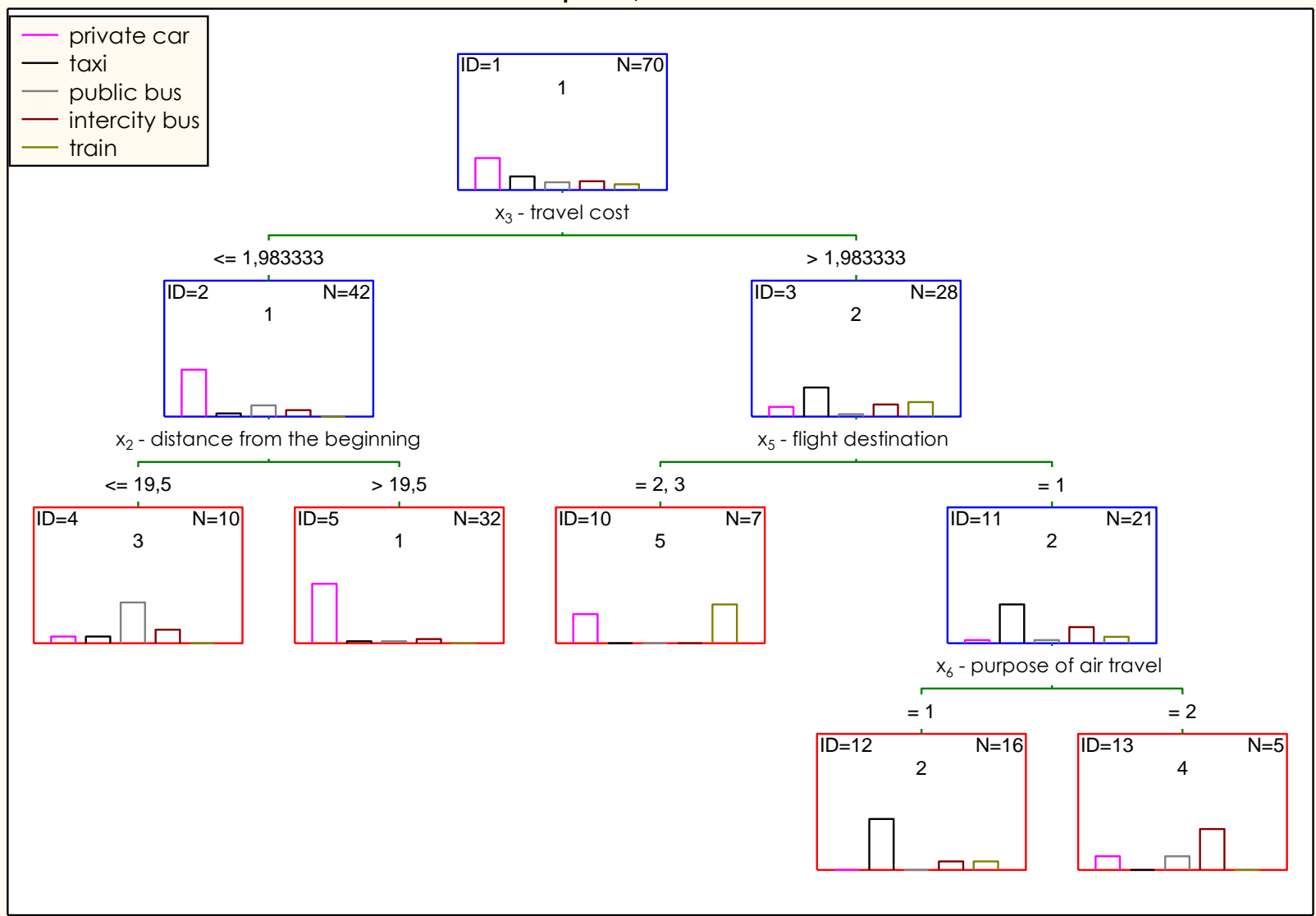

Fig. 6. Regression tree model for transport mode 
Source: own elaboration based on data from questionnaire (by Statistica 12.5 software)

\begin{tabular}{|c|c|c|c|c|c|c|}
\hline \multirow[t]{2}{*}{ No of node } & \multicolumn{6}{|c|}{$\begin{array}{l}\text { Results for terminal nodes } \\
\text { Dependent variable: transport mode } \\
\text { Options: Qualitative variable, Regressoion tree Nol }\end{array}$} \\
\hline & \begin{tabular}{|c|} 
Class \\
1 \\
\end{tabular} & $\begin{array}{c}\text { Class } \\
2\end{array}$ & $\begin{array}{c}\text { Class } \\
3 \\
\end{array}$ & $\begin{array}{c}\text { Class } \\
4\end{array}$ & $\begin{array}{c}\text { Class } \\
5\end{array}$ & $\begin{array}{c}\text { Total passengers } \\
\text { in ID }\end{array}$ \\
\hline $\mathrm{ID}=4$ & 1 & 1 & 6 & 2 & 0 & 10,00000 \\
\hline $\mathrm{ID}=5$ & 28 & 1 & 1 & 2 & 0 & 32,00000 \\
\hline $\mathrm{ID}=10$ & 3 & 0 & 0 & 0 & 4 & 7,00000 \\
\hline $\mathrm{ID}=12$ & 0 & 12 & 0 & 2 & 2 & 16,00000 \\
\hline $\mathrm{ID}=13$ & 1 & 0 & 1 & 3 & 0 & 5,00000 \\
\hline
\end{tabular}

Fig. 6. Results in terminal nodes for transport mode

Source: own elaboration based on data from questionnaire (by Statistica 12.5 software)

Regression tree model (fig.6) has divided respondents into 5 terminal groups: $I D=4, I D=5, I D=10, I D=12$ and $I D=13.46 \%$ of respondents belongs to group $I D=5.87,5 \%$ of them used private car when arriving to WAW. A very important point is that travel costs for this group were lower than 1,983 EUR. That may be surprising, as private car is said to be the most expensive transport mode. However, in simple statistical analysis before regression tree model, it could be notice that $100 \%$ passengers using private cars estimated their transport costs as 0,00 EUR. The second feature of ID=5 was distance to the airport from the beginning of the trip which was over $19,5 \mathrm{~km}$.

$I D=4$ is the group of $14 \%$ of respondents who most often use taxi to arrive to WAW. The travel distance is less than $19,5 \mathrm{~km}$ and travel costs are on the low level too. Then, they are rather passengers starting their travel from Warsaw districts located around the airport.

For three next groups, travel costs were over 1,983 EUR. Passengers travelling in medium-haul and long-haul flights ( $10 \%$ of respondents) chose mostly (57\%) train, however $43 \%$ passengers from this group travelled by private car (ID=10). Majority of short-haul flight passengers ( $17 \%$ from ID=12) whose purpose of air travel was private trip preferred to use taxi as transport mode to WAW.

There was only one group $(I D=13)$ in which majority of passengers used intercity bus and it is characterised by those whose travel costs were over 1,9833 EUR, they took short-haul flights however they travelled in business.

Summarizing this part, it must be pointed out that it was not possible for the model to create strictly homogenous groups of passengers which could be characterised in the terms of choice of transport mode.

\section{DISCUSSION}

Apart from the fact that air travel passengers are the very interesting group of people for researchers, primarily they create the significant target group for airport managers. For those, these are customers who use airport infrastructure in order to change the transport mode from land to air and vice versa. Airport as a complicated building construction with a lot of functions, should be well communicated with city, city centre, region etc. Good accessible however is difficult to define as each passenger can have different preferences of arriving to/departing from the airport. The basic seems to be the division of the passengers to the homogenous groups and classify the transport mode to the airport for them.

The several investigations for different purposes have been conducted to explain behaviour of passengers inter alia their preferences about transport mode to the airport. Preliminary research from WAW confirms the world studies, that the most preferable transport mode to the airport is a private car. The most significant factors influencing transport mode are also the same as on other researched airport and these are: cost travel and travel time but also distance to the airport from the beginning of the trip.

Unique, within city limits location of WAW is visible in choosing transport mode by surveyed passengers. Respondents living in Warsaw do not choose private cars as preferable. That may mean that Warsaw public transport provide sufficient solution for them. Nevertheless, majority of those who travel longer than 19,5km uses private cars. That may mean that people outside Warsaw do not have enough knowledge about convenient intercity transport to WAW. That is also confirmed by the fact that few passengers used intercity coach to arrive directly to WAW.

Surprisingly, people who travel by taxi to the airport have private purpose of the flight, from the other hand businessmen use intercity transport modes. This may be caused by the fact that the main 
business areas in Warsaw are located in the strict city centre next to the train station and in the near distance to WAW.

As the research are preliminary but the results presented some interesting cases, there is a need to continue this studies in the future. More detailed research could help both the airport management and city transport managers to adjust demand for the transport modes to WAW with respect to strategy of Warsaw public transport development.

In conclusion, in order to prepare the exact research and optimal report on the problem it is needed to increase the number of respondents which would ensures optimal and reliable results.

\section{ACKNOWLEDGMENT}

I would like to thank to MSc. Maria Zych-Lewandowska who spent her time and helped me with interviewing the passengers at Warsaw Chopin Airport.

\section{REFERENCES}

1. Foote, P.J., LaBelle, S.J. \& Stuart, D.G. (1997). Increasing rail transit access to airports in Chicago. Transportation Research. 1600, 1-9.

2. Ling Tam, M., Lam Tam, M. \& Lam, W.H.K. (2005). Analysis of airport access mode choice: a case study in Hong Kong. Journal of the Eastern Asia Society for Transportation Studies, Vol. 6, 708 - 723.

3. Mandle, P.B., Mansel, D.M. \& Coogan, M.A. (2000). Use of public transportation by airport passengers. Transportation Research, 1703, 83-89.

4. Foote, P.J., LaBelle, S.J. \& Stuart, D.G. (2007). Increasing rail transit access to airports in Chicago. Transportation Research Record: Journal of the Transportation, Research Board 1600, 1-9.

5. Caves, R.E., Ndoh, N.N. \& Pitfield, D.E. (1991). Route choice modelling applied to the choice between mature airports and emergent airports in their shadow. The 31st RSA European Congress, 1991.

6. Psaraki, V. \& Abacoumkin, C. (2002). Access mode choice for relocated airports: the new Athens International Airport. Journal of Air Transport Management, Vol. 8, 89-98.

7. Jou, R.C., Hensher, D.A, \& HsU, T.L. (2011). Airport ground access mode choice behavior after the introduction of a new mode: a case study of Taoyuan International Airport in Taiwan. Transportation Research Part E: Logistics and Transportation Review 47, 371-381.

8. Tam, M.L., Lam, W.H.K \& LO, H.P. (2011). The impact of travel time reliability and perceived service quality on airport ground access mode choice. Journal of Choice Modeling 4, 49-69.

9. Tsamboulas, D.A. \& Nikoleris, A. (2013). Passengers' willingness to pay for airport ground access time savings. Transportation Research Part A: Policy and Practice 42, 1274-1282.

10. Acar, G. (2013). Ground access to airports, case study: Port Columbus International Airport. Journal of Air Transport Management 30, 25-31.

11. Whitley, A. (2015). Using statistical learning to predict survival of passengers on the RMS Titanic. Kansas: Kansas State University Manhattan.

12. Breiman, L., Friedman, J.H., Olshen, R.A. \& Stone, C.J. (1993). Classification and Regression Trees. Chapman and Hall, 1993.

13. Gatnar, E. (2001). Nieparametryczna metoda dyskryminacji i regresji. PWN, Warszawa.

14. Łapczyński, M. (2002). Przyczynowa interpretacja drzew klasyfikacyjnych. Zależności przyczynowo-skutkowe w badaniach rynkowych i marketingowych, ed. Mynarski, S. Economic University in Cracow. 47-60.

\section{AUTHORS}

A. Gorecka is with the Warsaw University of Life Sciences - SGGW in Poland (e-mail: aleksandra_gorecka@sggw.pl). 